\title{
The Effect of Learning-by-Hiring on Productivity*
}

\author{
Pierpaolo Parrotta ${ }^{\dagger}$ and Dario Pozzoli ${ }^{\ddagger}$
}

\begin{abstract}
This article focuses on the phenomenon of inter-firm labor mobility as a potential channel for knowledge transfer. Using data from the Danish employer-employee register, covering the period 1995-2005, we investigate how knowledge carriers - technicians and highly-educated workers recruited from a donor firm - contribute to knowledge diffusion and enhanced productivity in the hiring (recipient) firm. Structural estimation of the hiring firms' production functions shows that the impact of the recruitment of knowledge carriers on a firm's value added is an increase of one to two percent. Several robustness checks confirm this finding.
\end{abstract}

JEL Classification: J24, J60, L20.

Keywords: Knowledge transfer, knowledge carrier, labor mobility, learning-by-hiring.

*We thank Tor Eriksson, Lars Geerdsen, Sanne Hiller, Hans Kongsted, Joep Konings, Simone Moriconi, Michael Rosholm, Davide Sala, Valerie Smeets, Måns Soderbom, Stijn Vanormelingen and Frederic Warzynski (alphabetical order) for helpful suggestions. We also thank the CEBR for the provision of data on Danish patent applications ascribed at EPO. Pierpaolo Parrotta acknowledges the financial support from the Graduate School for Integration, Production and Welfare. The usual disclaimer applies.

${ }^{\dagger}$ Aarhus University, Department of Economics, Hermodsvej 22, DK, 8230 Aabyhoj, Denmark; and University of Lausanne, Department of Economics, CH-1015 Lausanne, Switzerland. E-mail: pipa@asb.dk.

${ }^{\ddagger}$ Corresponding Author. Aarhus University, Department of Economics, Hermodsvej 22, DK, 8230 Aabyhoj, Denmark. E-mail: dpozzoli@asb.dk. 


\section{Introduction}

Knowledge can be defined as a fundamental resource employed in all valuable human activities. Its identification as an economic good has, for a long time, commanded considerable attention in research efforts (Antonelli, 1995). A group of models belonging to New Growth Theory suggested different frameworks to understand and describe the role of knowledge in driving productivity and thereby fostering economic growth. Several macroeconomists (Romer, 1990; Grossman and Helpman, 1991; Aghion and Howitt, 1992) have identified the transmission of knowledge as main driver of sustained economic growth.

A potential channel of knowledge transfer is inter-firm labor mobility. Most of a firm's knowledge set is not codified but is characterized by a tacit nature. A valuable part of such a tacit, or less articulated, knowledge is likely to be embodied in highly-educated or skilled workers, a knowledge acquired through job tenure. Thus, moving from one firm to another, these individuals carry the acquired knowledge and apply it to new contexts. It can hardly be transmitted in a different way, as it is not codified but is inherent in the routines and procedures of a firm's production. Moreover, the transfer of this acquired knowledge, which informally belongs to the firm, cannot be effectively prevented by patents or other forms of intellectual property rights, which can only protect forms of codified or, at least, articulated knowledge (Petit and Tolwinski, 1996; Gilson, 1999). This process of knowledge transmission via inter-firm labor mobility is known as learning-by-hiring $(\mathrm{LbH})$.

In the literature, very little evidence exists of the effect of $\mathrm{LbH}$ on firm performance. Previous work has found a positive impact of specific categories of recruited workers on firms' patenting activity. However, the distribution of patenting firms is strongly concentrated and knowledge transfers may or may not influence patenting activity. But because acquired knowledge can affect firm productivity and it is a broader measure of performance, it seems opportune to investigate the effects of LbH on such a measure. This allows us to take a large number of firms into account and thereby include a representative sample of both production and service sectors.

This article broadens earlier investigations to include the variable LbH, and studies how workers newlyrecruited from other firms affect productivity in the hiring firm. Specifically, the analysis focuses on the role of employees with a tertiary (Bachelor's, Master's or post-graduate degree) or vocational/technical education. Furthermore, we impose that these knowledge carriers receive a higher wage than that received in their previous job. These higher wages (i.e. premium) signal the firm's willingness to acquire the knowledge carried by the recruited worker.

However, the receipt of knowledge transfer does not occur simply with the recruitment of a knowledge carrier. A successful transfer may depend on two relevant features: intensity and proximity. Intensity is 
defined as a concave function of the number of workers coming from a given donor firm, and proximity weights each worker's hire by the technological closeness between the donor and hiring firm pair (Jaffe, 1986; Adams, 1990; Inkmann and Pohlmeier, 1995; Cincera, 2005). Proximity is computed in a metric space generated by vectors, the elements of which are firms' shares of patent applications in the eight main technological areas defined by the International Patent Classification (IPC). ${ }^{1}$

The production function parameters are estimated in accordance with the algorithm proposed by Ackerberg et al. (2006), who address both collinearity and endogeneity issues. Specifically, firms are allowed to observe productivity shocks before hiring knowledge carriers, which ensures that the contribution of this input to productivity is estimated properly.

Findings from our empirical analysis support our definition of knowledge carriers, and are confirmed by several robustness checks. The effect we are interested in, i.e. how knowledge transfers enhance firm productivity, is significantly positive and the inclusion of intensity and proximity in the LbH measure seems to better explain productivity. Our findings also show that the LbH contribution to productivity is relevant: a unitary increase induces on average a growth between one and two percent in firms' productivity.

Overall, the results are consistent with New Growth theoretical models, which place a strong emphasis on knowledge diffusion. In particular, our findings suggest improvements in the modeling of the process of knowledge transfer at the micro level, stimulating further analyses on the additional effects associated with inter-firm labor mobility.

The structure of the article is as follows: Section 2 briefly reviews the relevant literature; Section 3 describes the data; Section 4 provides details on the empirical strategy; Section 5 presents the main results; Section 6 presents the sensitivity analysis; and Section 7 presents our conclusions and suggestions for further research.

\section{Literature background}

$\mathrm{LbH}$ refers to valuable knowledge transferred via inter-firm labor mobility. It is defined as the acquisition of knowledge from other firms through the hiring of experts (Song et al., 2003). In accordance with this definition, the benefits of LbH should not be confused with either the usual high labor productivity engendered by newly-employed experts or potential externalities associated with scale effects. As we have defined here, inflows of knowledge carried by technicians and highly-educated workers are typically forms of developed but not codified knowledge. As a consequence, what is carried by these mobile workers cannot spill over freely. Hence, the impact of $\mathrm{LbH}$ can only be precisely quantified if a donor and a recipient firm are identified.

\footnotetext{
${ }^{1}$ Human necessities, performing operations/transporting, chemistry/metallurgy, textiles/paper, fixed construction, mechanical engineering/lighting/heating/weapons/blasting, physics and electricity.
} 
Without a matched employer-employee register, then, it is not possible to estimate the contribution of this knowledge transfer through any kind of firm performance indicator. Though such registers are now available, the use of inter-firm labor mobility as a learning mechanism has not, until now, received particular attention.

Although their study is not conducted at the firm level, Almeida and Kogut (1999) find that the mobility of engineers holding major patents affects the intra- and inter-regional pattern of patent citations, which is considered a proxy of knowledge flow. Mapping US semiconductor plant clusters through the use of county level establishment and employee data, they illustrate how the mobility of engineers partially explains innovations occurring among regional clusters. Rosenkopf and Almeida (2003) take this one step further. Tracking both inter-firm mobility of engineers and patent citations in the US semiconductor industry, their analysis concludes that the effectiveness of labor mobility in terms of knowledge flows increases with the degree of technological distance between firms. These findings are confirmed and reinforced by Song et al. (2003). In this work they investigate the conditions under which labor mobility is more likely to facilitate knowledge transfers. Results seem to support the hypotheses that $\mathrm{LbH}$ is more effective (in terms of contribution to patent production) when (i) the recipient firm is less path dependent ${ }^{2}$ (ii) mobile engineers carry knowledge distant from that characterizing the recipient firm; and (iii) knowledge carriers work in non-core technological areas in the recipient firm. Thus, inter-firm labor mobility may mitigate difficulties of learning in firms characterized by research in distinct technological areas and increase the possibility of benefiting from external knowledge.

A different perspective is investigated by Kim and Marschke (2005). Using a sample of US firms, they analyze how the risk of a key employee's departure reduces the firm's R\&D expenditure and/or increases its patenting propensity. Their findings are consistent with the statement that firms use patents to minimize the negative effect associated with the departure of an engineer or a scientist and helps to explain different propensities among firms to patent. Maliranta et al. (2010) provide further evidence that R\&D workers transmit valuable knowledge. Using Finnish employer-employee data, the authors find that firms hiring workers previously engaged in $\mathrm{R} \& \mathrm{D}$ activities may increase productivity and profitability in the hiring firm even if these workers do not perform R\&D activity in their new job. This finding is interpreted as evidence that mobile $R \& D$ workers may transmit knowledge that can be readily copied and implemented even when not engaged in a strong research effort.

A crucial study for the work presented in this article is Kaiser et al. (2008). They constructed a data set in which the number of patent applications sent by Danish firms to the European Patent Office (EPO) was matched to the Danish employer- employee register. They looked at how labor mobility affects innovation in

\footnotetext{
${ }^{2}$ Path dependence is measured as the number of self-cited patents. Self-citing occurs when a patent filed by a firm cites another patent from the same firm (Song, et al., 2003).
} 
Danish firms, and specifically how the composition and past patenting experience of labor inflows influence firm-level patenting activity. They split the firm workforce into "R\&D workers" and "non-R\&D workers". Whereas the former class identifies employees with Bachelor's or Master's degrees in the natural sciences and technical fields, the latter one identifies individuals with the same level of education in the humanities. The results of their analysis support the idea that mobile $R \& D$ workers contribute more to firm patenting activity than immobile $R \& D$ workers do. This effect is stronger in the case where the $R \& D$ worker has been previously employed in a patenting firm.

Although Kaiser et al. (2008) more formally assess the quantitative effects of labor mobility on innovation, they only focus on patenting activity as a proxy for innovation efforts. Because they constrain the amount of knowledge transferred to patent applications or grants only, the entire fruit of a knowledge transfer is only related to patents. Moreover, since the patenting activity is particularly concentrated among firms (this holds even more strongly in Denmark), the number of firms observed in the sample may not be representative of the entirety of production activities in which relevant, valuable knowledge is inherent.

\section{Data}

\section{Data sources}

The data set used in our empirical analysis has been constructed by merging information from three different main sources. The first data source is the "Integrated Database for Labor Market Research" (IDA) provided by Statistics Denmark. IDA is a longitudinal employer-employee register containing valuable information (age, demographic characteristics, education, labor market experience, work experience and earnings) on each individual employed in the recorded population of Danish firms during the period 1980-2005. Apart from deaths and permanent migration, there is no attrition in the data set. The labor market status of each person as of November 30 is recorded as the relevant datum for each person for that year. The retrieved information has been aggregated at the firm level and consequently merged with variables such as firm location (county), size and related industry. ${ }^{3}$

The second data source is "Regnskab", which lists firms' business accounts, as provided and compiled by Statistics Denmark. It covers the construction industry from 1994, manufacturing from 1995, wholesale trade from 1998, and the remaining part of the service industry from 1999. Data in "Regnskab" are aggregates of yearly financial items, which are crucial for the estimation of the production function. In particular, it is possible to retrieve information on sales, intermediate goods or materials, fixed assets and profits. ${ }^{4}$

\footnotetext{
${ }^{3}$ In our empirical analysis we exclude the following sectors: i) agriculture, fishing and quarrying; ii) electricity, gas and water supply, and iii) public services.

${ }^{4}$ Statistics published in "Regnskab" have been gathered in several ways. All firms with more than 50 employees or profits higher than a given threshold have been surveyed directly. The other firms are recorded in accordance with a stratified sample strategy. The surveyed firms can choose whether to submit their annual accounts and other specifications or fill out a questionnaire. To
} 
The third data source identifies patent applications and grants awarded to Danish firms by the EPO during the period 1978-2003. Access to such data has been made possible by the Centre for Economic and Business Research (CEBR). ${ }^{5}$ A total of 12,109 patent applications has been recorded, and includes 2,822 Danish non-person patent applicants. ${ }^{6}$ This allows us to compute measures of technological proximity based on the number and areas of firms' patent applications.

\section{Variables}

This section describes the variables used in the empirical analysis. As the purpose of this article is to provide evidence concerning the impact of $\mathrm{LbH}$ on firm productivity, attention is devoted primarily to measures indicating inter-firm knowledge transfers via labor mobility.

Combining information from these sources, the final data set allows for the mapping of all mobile workers aged 18 to 60. To identify knowledge carriers, we focus only on employees holding either a tertiary (at least, Bachelor's degree) or a vocational/technical education. In addition, we require that i) the mobile worker has experienced a real ${ }^{7}$ wage increase of at least five percent after moving; ii) the real annual wage of the current job is higher than the average of real wages received in the previous three years ${ }^{8}$ iii) the incomer's wage is greater than the average wage recorded in the recipient firm; iv) the donor firm is not downscaling the labor force $;^{9}$ and v) the period of unemployment preceding the start of the new job is less than 3 months. These conditions can be interpreted as a signal of a precise and intentional recruitment strategy implemented by the recipient firm. In fact, it is assumed that every recipient firm, aware of the expected benefit deriving from the recruitment of knowledge carriers, is willing to pay an opportune wage premium.

Three measures of inter-firm knowledge transfers have been defined for this article. The first measure is constructed as the sum (count) of all knowledge carriers moving from donor firm $d$ to recipient $r$ :

$$
L b H \_ \text {count }_{r}=\sum_{d=1}^{D} k_{d r},
$$

where $k_{d r}$ is the total number of knowledge carriers moving from a donor firm $d$ to a recipient firm $r$ and $D$ represents the total number of donor firms.

Though quite similar to the first measure, the second one accounts for the hiring of more than one knowledge carrier from a single donor firm and weights the number of knowledge carriers using a concave function.

\footnotetext{
facilitate responses, questions are formulated similarly to those in the Danish annual accounts legislation.

${ }^{5} \mathrm{An}$ independent research centre affiliated with the Copenhagen Business School (CBS).

${ }^{6}$ Patenting firms are here considered for the period 1995-2003 and belong to the following industries: manufacturing of food, beverages and tobacco; manufacturing of textiles and leather; manufacturing of wood products and printing; manufacturing of chemicals, plastic products; manufacturing of other non-metallic mineral products; construction; wholesale, except motor vehicles; transport; finance and insurance; rentals and sale of real estate; and business activities. More detail concerning the construction and composition of the dataset can be found in Kaiser et al. (2005).

${ }^{7}$ The annual wage is deflated using the price deflator for the year 2000.

${ }^{8}$ Or two, in the case the third year is missing.

${ }^{9}$ The yearly reduction in the total labor force is imposed to be smaller than one percent.
} 
Concavity is ensured by applying a concave transformation to the total of qualified workers (technicians and highly-educated employees) coming from donor firm, $d$ :

$$
L b H \_ \text {concave } r=\sum_{d=1}^{D} k_{d r}^{\left[\left(k_{d r}-1\right) / 2 k_{d r}\right]} .
$$

This implies that $L b H \_$concave $_{r}$ increases less than proportionally with respect to the total number of qualified workers leaving a given donor firm, $d$, and being employed in the same recipient firm, $r$. The first and second measures coincide in the case that only one worker moves between a specific donor-recipient firm pair. This means that the concave version adjusts according to the intensity of each inter-firm knowledge inflow: two workers from the same donor firm will together transfer less than double the amount of knowledge a single worker transfers. Hence, a larger amount of embodied knowledge is brought by the first carrier from a given donor firm. The second measure also attributes more public good features to the knowledge inflow, even though it is still characterized by partial-excludability ${ }^{10}$ and a low degree of appropriability.

The third and most complete measure introduces a further element represented by the technological proximity index $\psi$ :

$$
L b H \_p r o x_{r}=\sum_{d=1}^{D} \psi(d, r) k_{d r}^{\left[\left(k_{d r}-1\right) / 2 k_{d r}\right]} .
$$

This allows us to correct the intensity of inter-firm labor mobility for the technological proximity between donor and recipient firms (Jaffe, 1986; Adams, 1990; Inkmann and Pohlmeier, 1995; Cincera, 2005). Thus, the level of exploitability associated with labor mobility could depend on the degree of similarity in the technological knowledge characterizing the donor-recipient firm pair. To measure the proximity between firms' technological capabilities, a technological space needs to be defined. In the present work, the generator vector $f$ is composed of elements reflecting firms' stocks of patent applications in the eight main IPC technological areas noted earlier. Technological proximity here is computed using the uncentered correlation suggested by Jaffe (1986):

$$
\psi(d, r)=\frac{f_{d} f_{r}^{\prime}}{\left[\left(f_{d} f_{d}^{\prime}\right)\left(f_{r} f_{r}^{\prime}\right)\right]^{1 / 2}} .
$$

If the donor and recipient firms coincide perfectly in the generated technological space, then $\psi(d, r)=1$. Conversely, if they do not overlap at all, the weight takes on the value 0. However, it is worth underlining that technological proximity can only be used for patenting firms.

In addition to these three described measures, the empirical analysis includes the following variables:

\footnotetext{
${ }^{10}$ Non-excludability means that once a good has been produced, it is not possible to prevent other people from gaining access to it (more realistically, it is costly for the provider to exclude unauthorized users).
} 
valued added ${ }^{11}$, materials (intermediates), capital stock (fixed assets), labor force, dummies for counties, ${ }^{12}$ industries ${ }^{13}$ and years. Using the price deflator for the year 2000, the monetary values were converted in real terms. Additional explanatory variables include shares of specific categories of employees.

\section{Descriptive statistics}

With data and variables described, descriptive statistics can be discussed. In the following and the main analysis that follows, we exclude (a) firms with imputed accounting variables and (b) values referring to the last (99th) percentile of the LbH distribution. This exclusion strengthens the reliability of our empirical investigation. However, firms with imputed accounting variables are later taken into account in the sensitivity section, to check their actual influence on the main results.

Table 1 reports number of observations, median and mean values, and standard deviations of the accounting, workforce and sector variables, for the whole sample and by firm size. Size is classified by three categories: Size1, Size2 and Size3, referring to firms with less than 50, between 50 and 99 and more than 99 employees, respectively. Despite the large number of observations, more than 95 percent are accounted for by firms with less than 50 employees. This size distribution of firms is consistent with the structure of the Danish industrial private sector, which is largely dominated by small-sized firms. ${ }^{14}$ Although not all industries were recorded during the first years of the sample period, percentages reported among industries approximately reflect aggregate data for the same time span. Whereas observations for the construction and manufacturing industries are over-represented, the opposite is true for the financial and business sectors. However, that is entirely explained by the unbalanced structure of the data set: construction and manufacturing were the only industries recorded in the first years, while financial and business were included only in the last ones.

The distance between median and mean values for the accounting variables (reported in thousands of real DKK) and workforce variables is considerable, indicating a certain degree of skewness (and polarization) among firms in the sample. This is also confirmed by the notable size of the standard deviations. Whereas Size1 firms account for the highest shares of workers with vocational education, Size2 firms account for the largest proportions of managers and younger employees, and Size3 firms employ the highest proportion of

\footnotetext{
${ }^{11}$ It is computed as the difference between total sales and materials.

${ }^{12}$ Copenhagen, Frederiksborg, Roskilde, West Zealand, Storstrom, Bornholm, Funen, South Jutland, Ribe, Vejle, Ringkobing, Aarhus, Viborg, North Jutland.

${ }^{13}$ Manufacturing of food, beverages and tobacco; manufacturing of textiles and leather; manufacturing of wood products and printing; manufacturing of chemicals and plastic products; manufacturing of other non-metallic mineral products; manufacturing of basic metals and fabricated metal products; manufacturing of furniture; manufacturing n.e.c.; construction; sale and repair of motor vehicles, sale of automotive fuel; wholesale except for motor vehicles; retail trade of food; department stores; retail sale of pharmaceutical goods and cosmetic articles; retail sale of clothing and footwear; other retail sale, repair work; hotels and restaurants; land transport and transport via pipelines; water transport; air transport; supporting transport activities; post and telecommunications; finance; insurance; activities auxiliary to finance; real estate activities; renting of transport equipment and machinery; computer and related activities; research and development; consultancy activities; and cleaning activities.

${ }^{14}$ The structure of the Danish firm population is mainly composed of small and medium-sized companies. Enterprises with less than 50 employees account for 97 per cent of the total number of firms and represent 42 per cent of the total employment in manufacturing and services. Thus, it seems reasonable to distinguish between SME and larger enterprises using a limit of 100 employees. However, compared to the other Nordic countries, Denmark presents fewer micro firms (1-9 employees): these represent 87 per cent of firms against 92 and 94 percent recorded in Finland and Sweden, respectively (OECD, 2005).
} 
highly-educated workers. The defined variables change in value as expected among the definitions of inter-firm labor mobility. The count measure presents the higher mean value, and both count and concave measures increase their standard deviation with respect to firm-size. LbH_prox is not reported in Table 1 because it refers only to firms that applied for a patent at least once during the observation period.

Table 2 reports the median, mean and standard deviation of the main variables according to firms with and without patents. Patenting firms typically exhibit a larger size and significantly higher accounting values than non-patenting ones. The value of average capital stock is about 25.8 times that of non-patenting firms. Significant differences in worker skill levels are also noted for the two firm groups. Larger shares of highlyeducated employees are recorded for the patenting firms; larger shares of technicians or vocational workers are recorded for the non-patenting firms.

\section{Empirical strategy}

\section{Issues on production function estimation}

The literature on firm-level production functions has identified a number of problems associated with the estimation of input productivity. The most common issue with the estimation of such parameters concerns simultaneity, i.e. the endogeneity of inputs. This occurs when productivity shocks, unobserved by econometricians, are observed by firms and allow management to reallocate resources in the production process accordingly. If that is the case, such shocks may be taken into account by firms to maximize their profits or minimize their costs. Specifically, positive (negative) productivity shocks induce firms to expand (reduce) output, which requires a higher (lower) quantity/quality of inputs for production. This implies that OLS estimates of coefficients on inputs observed by econometricians are biased and inconsistent, and error terms and regressors are correlated. Moreover, it is widely acknowledged that whereas fixed-effects (FE) estimation techniques (Mundlak, 1961) take account of firm heterogeneity, they do not solve the simultaneity problem when productivity shocks fluctuate over time.

Several remedies have been proposed to cope with simultaneity, including the recent structural approach advocated by Olley and Pakes (1996) (OP henceforth) and Levinsohn and Petrin (2003) (LP henceforth). ${ }^{15}$ Both OP and LP suggest semi-parametric methods based on (i) the identification of a proxy variable, which is assumed to be a function of time-varying productivity shocks (total factor productivity) and (ii) the definition of conditions under which this function is invertible. The idea behind this is to infer total factor productivity by using observed firms' input choices.

OP present a two-step estimation method: in the first step, semiparametric methods are used to estimate the coefficients on the variable inputs along with the nonparametric function linking productivity to capital

\footnotetext{
${ }^{15}$ See Ackerberg et al. (2006) for a survey.
} 
and investment; in the second step, parameters on capital inputs are identified under the assumptions of the dynamics of the productivity process ${ }^{16}$ (Wooldridge, 2009). However, OP's estimation method presents two major drawbacks. First, because adjustment costs create lumpiness in investment levels, these levels may not respond smoothly to productivity shocks. Second, OP approach excludes firms reporting zero investment levels: it induces a de facto truncation bias. To overcome these drawbacks, LP use a measure of intermediate inputs as a proxy for investment levels. Many benefits are associated with this choice. First, changes in intermediate inputs do not typically involve adjustment costs; intermediate inputs therefore respond better to productivity shocks than investments do. Second, intermediate inputs provide a simple link between estimation strategy and economic theory because they do not typically represent state variables. Third, because intermediate inputs are almost always used in production, LP's approach circumvents the abovementioned data truncation problem. Moreover, LP suggest three specification tests for evaluating the proxy's performance (Petrin et al., 2004). However, the coefficient on the proxy is recovered at the second stage rather than in the first, as in the OP approach.

Although, the OP and LP approaches have been broadly used for identification of the production function, each approach is vulnerable to collinearity and identification problems. As pointed out by Söderbom and Bond (2005) (SB henceforth), both approaches can perform poorly as they do not fully control for unobserved productivity shocks. SB provide evidence showing the impossibility of identifying the parameters from crosssection variation if all inputs are perfectly flexible and factor prices are constant. Similarly to SB, Ackerberg et al. (2006) (ACF henceforth) explain how collinearity between labor and non-parametric terms (capital and proxy variable) interferes with the identification of the labor coefficient. To address these collinearity and identification issues, ACF suggest an alternative estimation procedure in which labor coefficients are estimated in the second stage. ${ }^{17}$ A key point of the ACF procedure is that it allows the estimation of production functions in which all inputs are assumed not to be perfectly variable. In this case, a first stage is needed just to net out the error component in the production function (Ackerberg et al., 2006).

\section{Empirical model}

In our analysis, productivity is obtained from a Cobb-Douglas production function with additive firm heterogeneity, where the real value added $\mathrm{Y}$ is the dependent variable. The production factors are labor force L, capital K, our central variable, LbH, additional variable inputs X (shares of managers, wage earners, males, highly-educated workers, technicians, and differently aged workers belonging to the employees' age distribution quartiles). We also specify control variables, C, identified by partial/total foreign ownership, year,

\footnotetext{
${ }^{16}$ Productivity is assumed to follow a first order Markov process.

${ }^{17}$ If a linear $\mathrm{AR}(1)$ model for productivity is implemented, then the second stage in ACF would literally be the dynamic COMFAC model adopted by Blundell and Bond (2000) (Söderbom, 2009). Wooldridge (2009) proposes an alternative implementation of $\mathrm{OP} / \mathrm{LP}$ that involves estimating the first and second stages simultaneously. This can easily be extended to ACF methodology by simply adding labour input to the first stage non-parametric function.
} 
3-digit industry classification and regional dummies because they can potentially affect productivity. For the sake of simplicity, we omit these controls, C, from the following log-linear production function definition:

$$
\ln Y_{i t}=\mathrm{cons}+\alpha \ln L_{i t}+\beta \ln K_{i t}+\gamma L b H_{i t}+\delta X_{i t}+u_{i t} .
$$

The variable $\mathrm{L}$ represents the total number of workers in a given firm, and includes potential knowledge carrier inflow, LbH. The coefficient on $\mathrm{LbH}$, then, should not be interpreted as (confused with) human capital or partial labor force contribution to firm productivity: it is the effect of the valuable knowledge transferred via labor mobility to the hiring firm. The error term $u_{i t}$ represents a time-varying firm-specific effect, $v_{i t}$ (unobserved by econometricians), and an idiosyncratic component, $\varepsilon_{i t}$. Specifically, we assume that inputs are uncorrelated with $\varepsilon_{i t}$ :

$$
E\left(\varepsilon_{i t} \mid l_{i t}, k_{i t}, L b H_{i t}, X_{i t}, m_{i t}, l_{i t-1}, k_{i t-1}, L b H_{i t-1}, X_{i t-1}, m_{i t-1}, \ldots, l_{i 1}, k_{i 1}, L b H_{i 1}, X_{i 1}, m_{i 1}\right)=0,
$$

with $t=1,2, \ldots, T$, and where $m$ refers to our proxy variable (materials) and lower-case letters to log-variables. Because past values of $\varepsilon_{i t}$ are not accounted for in the conditioning set, we allow for serial dependence in the pure shock term. However, we need to restrict the dynamics in the productivity process:

$$
E\left(v_{i t} \mid v_{i t-1}, v_{i t-2}, \ldots, v_{i 1}\right)=E\left(v_{i t} \mid v_{i t-1}\right) \equiv g\left(v_{i t-1}\right)
$$

with $t=1,2, \ldots, T$. As in ACF's approach, we assume material input to be chosen after labor input. In addition, we assume that $\mathrm{LbH}$ and the additional variable inputs, $\mathrm{X}$, are set before or at the same time as material input is chosen. As a result, material demand will not only be a function of capital and productivity, but also of $l, L b H$ and $X$ :

$$
m_{i t}=f\left(k_{i t}, v_{i t}, l_{i t}, L b H_{i t}, X_{i t}\right)
$$

and assuming that the material demand function is strictly increasing in productivity shock $v_{i t}$, we get

$$
v_{i t}=f^{-1}\left(k_{i t}, m_{i t}, l_{i t}, L b H_{i t}, X_{i t}\right) .
$$

The key advantage of this approach is that it allows, for example, our key variable, $L b H$, to have dynamic implications or to depend on unobserved input price shock that could potentially be serially correlated over time. In fact, it seems reasonable to assume that the hiring and firing costs for labor or the fixed costs of setting up the recruitment and hiring of a knowledge carrier can last longer than a period. Plugging the 
inverse material demand into the production function, we get the first-stage equation, which here serves only to separate $v_{i t}$ from $\varepsilon_{i t}$,

$$
y_{i t}=\mathrm{cons}+\alpha l_{i t}+\beta k_{i t}+\gamma L b H_{i t}+X_{i t}+f^{-1}\left(k_{i t}, m_{i t}, l_{i t}, L b H_{i t}, X_{i t}\right)+\varepsilon_{i t}
$$

The function $f^{-1}(\cdot)$ is proxied with a polynomial in materials, capital, labor, $L b H_{i t}$ and $X_{i t}$. Thus, the estimated output net of the idiosyncratic component is used to identify parameters on inputs in the second stage. Recalling that $v_{i t}$ is a first-order Markov process, we define $a_{i t}$ as an innovation that can be correlated with current values of the proxy variable $m_{i t}$ and inputs $l_{i t}, L b H_{i t}$ and $X_{i t}$ :

$$
a_{i t}=v_{i t}-g\left(v_{i t-1}\right)
$$

where $a_{i t}$ is mean independent of all information known at $t-1$ and $g(\cdot, \cdot)$ is proxied also with a low-degree polynomial in dependent variables. Given our timing assumption, we suggest using the moments:

$$
E\left[\begin{array}{cc} 
& k_{i t} \\
& l_{i t-1} \\
a_{i t} \mid & L b H_{i t-1} \\
& X_{i t-1}
\end{array}\right]=0
$$

to identify coefficients on $k, l, L b H$, and $X$.

\section{Results}

The main findings from the empirical analysis are reported in Table 3. Columns 1 and 4 show capital and labor elasticities for non-patenting and patenting firms, respectively, for specifications that include $l$, $k$, and control variables, $C$, only. These elasticities do not substantially differ from elasticities reported for specifications in columns $2,3,5,6$ and 7 , all of which include a measure of $\mathrm{LbH}$ and X. ${ }^{18} \mathrm{~A}$ higher (lower) capital (labor) contribution is recorded for patenting firms.

Coefficients associated with the $\mathrm{LbH}$ measures in columns 2, 3, 5, 6, and 7 represent semi-elasticities since our variables are not in logarithms. This choice is founded on the fact that LbH takes on the value 0 for the majority of observations. Thus, any possible transformation of LbH measures could possibly affect the associated estimated parameters. As expected, LbH affects firm productivity positively, and its contribution is larger once intensity and proximity of transfers are taken into account. LbH semi-elasticity is always

\footnotetext{
${ }^{18}$ Findings for the sample of patenting firms are obtained by using a parsimonious specification: X only includes the share of highly educated workers and technicians.
} 
significant: it varies between one and two percent for the count and concave indexes. The increase in the coefficient on LbH is particularly high when technological proximity is introduced, which, however, implies the exclusion of non-patenting firms. The comparison of the magnitudes of the coefficients on the LbH measures across different specifications is not informative for deciding which measure better explains the effect of learning-by-hiring on productivity. To determine the best measure, we need to compare the goodnessof-fit for each reported specification that includes an LbH component. Following Windmeijer (1995), the goodness-of-fit here is computed as the correlation between predicted and actual values of the dependent variable. Comparing columns 4, 5,6 and 7, we find slightly larger improvements in the goodness-of-fit when the technological proximity between donor and recipient firm is accounted for. That supports the relevance of the technological proximity weight $\psi(d, r)$ when calculating the LbH index.

However, the relevance of our findings crucially depends on whether the donor firms experience eventual productivity losses due to the outflow of qualified employees. In fact, gains from LbH may simply compensate such losses, describing only one side of a zero-sum phenomenon. Results reported in columns 8, 9, and 10 of Table 3 are not consistent with a hypothesis of productivity losses for donor firms. Specifically, the parameter on the variable measuring the outflow ${ }^{19}$ of qualified workers is close to zero and never statistically significant. In these regressions, we treat employee outflow as an exogenous variable given that the knowledge carrier decision to be recruited by another firm is not affected by donor firm actions. Parameters on the LbH measures remain significant and stable. In most cases, the parameters increase slightly in value.

Table 4 reports findings from regressions at the 1-digit industry level. Again, we evaluate the effects on productivity using the three LbH measures, though the estimation of the parameter on LbH_prox can only be carried out for manufacturing and financial \& business service sectors because of the low number of observations of patenting firms in the other industries. It is found that the LbH contribution to productivity varies as expected across industry sectors. Specifically, the contribution is particularly high for the financial \& business service sector, but not always significant for the construction and transport sectors. Positive and slightly below the overall average, $\mathrm{LbH}$ effects are recorded also for manufacturing and wholesale \& retail trade sectors. Overall, the relevance of the LbH contribution to firm productivity is confirmed in this analysis at the industry level.

\section{Sensitivity analysis}

Several, precise conditions have been imposed on the definition of knowledge carriers in order to capture as precisely as possible the real contribution of knowledge transfer to firm productivity. Aware that the criteria

\footnotetext{
${ }^{19}$ Obviously, the concavity and proximity features do not apply for outflows. Therefore, employee outflow is a count measure.
} 
and conditions have been reasonably assumed, but assumed nonetheless, in this section we refine or relax these criteria and conditions, and then check whether such modifications influence the size and significance of the LbH effects.

We implement five refinements: (i) we impose a yearly wage premium of at least 10 percent for knowledge carriers - this increases the strength of the wage increase condition (previously set at five percent) on the willingness to be recruited; (ii) a zero-downsizing of the firm labor force is held at zero. In the main analysis downsizing of the firm labor force is limited to lower than one percent; (iii) we exclude all knowledge carriers with vocational education as well as those with degrees in the humanities and social sciences; (iv) knowledge carriers moving from part-time to full-time jobs are disregarded; and (8) there is no unemployment period between jobs, in contrast to the maximum period of three months allowed in the original analysis. The results of these refinements are presented in Table 5 . In refinements iii- $v$, the coefficients on the LbH effects improve. In refinement i, LbH_prox increases substantially but is not statistically significant. Refinement $i i$ does not result in any substantial change in parametric value nor statistical significance.

We implement only one but crucial relaxation: the wage criteria are excluded. This allows us to check whether the increase in the carriers' wages, and the positive differentials between them and the average wages in the recipient firm, are the only drivers of higher firm productivity. Our findings reject such a hypothesis. Although knowledge carriers typically are highly productive, their contribution to firm productivity in terms of knowledge transfers may not be imputed to their labor productivity, which is often associated with the earned wage.

As a further check, we evaluate how parameters on $\mathrm{LbH}$ measures change if we do not exclude firms with imputed values in for the accounting variables. The first three columns of Table 6 show that estimated semi-elasticities on $\mathrm{LbH}$ measures are very stable. In the fourth column, we test the weighting function, attributing more weight to technological distance rather than closeness. Specifically, we redefine LbH_dist, simply replacing $\psi(d, r)$ with $1-\psi(d, r)$. We find no evidence to favor technological distance as an appropriate weighting function, confirming our original assumption.

\section{Discussion and conclusions}

This article investigates the consequences of LbH on firm productivity. Specifically, the impact associated with the transfer of knowledge through inter-firm labor mobility is analyzed. In such a perspective, technicians and highly-educated workers are viewed as potential knowledge carriers. Their role allows enterprises to benefit from knowledge generated in other firms. However, knowledge transfers may not be pure externalities if recipient firms need to pay a wage premium to induce each inter-firm flow. To assess these learning effects, 
we estimate firm productivity following the algorithm suggested by Ackerberg et al. (2006).

Our findings support the assumption that LbH enhances productivity at the firm level, confirming the importance of external knowledge as a production factor. Specifically, we find that a unitary change in $\mathrm{LbH}$ can induce an average growth in firm productivity between one and two percent. The recruitment of a knowledge carrier can increase a firm's value added on average between real DKK 56,360 and DKK 112,710 (about USD 6,988-13,977 in the base year). In median terms, the same effect translates into a value added increase between real DKK 15,965 and DKK 31,930 (about USD 1,980-3,960 in the base year). This effect is greater when we allow for technological proximity between donor and recipient firms when measuring the exploitability of knowledge flows. It turns out that on average a unitary change in LbH_prox is related to more than a five percent increase in patenting firms' productivity. However, it is worth remembering that a unitary change in the most complete measure (with weights for both intensity and proximity) may potentially correspond to the recruitment of several knowledge carriers.

Our empirical analysis sheds light on the existence of knowledge exchange via labor mobility between any pair of enterprises, rejecting the hypothesis that this phenomenon involves only strongly research-based firms, as stressed in previous studies. We provide evidence that firms focusing on this aspect of the recruitment may gain external knowledge and exploit procedures and routines previously acquired in other enterprises with similar technological profiles. In fact, unlike the results reported in Rosenkopf and Almeida (2003) and Song et al. (2003), we find that closeness in firms' technological profiles is more important than distance, at least in a short-run perspective. Moreover, we devote particular attention not only to the hiring of workers holding degrees in natural sciences, but also to the hiring of those with a vocational education or with degrees in the social sciences and the humanities. Our findings suggest that knowledge transfers are not determined exclusively by workers having a tertiary education in natural or applied sciences, as assumed in the majority of articles in the literature. Several robustness checks corroborate our results and reinforce the reliability of these conclusions. 


\section{References}

[1] Ackerberg, D., CAves, K., And Frazer G. "Structural Identification of Production Functions." Mimeo UCLA Department of Economics, 2006.

[2] AdAms, J.D. "Fundamental Stocks of Knowledge and Productivity Growth." Journal of Political Economy, Vol. 98 (1990), pp. 673-702.

[3] Aghion, P. And Howitt, P. "A Model of Growth through Creative Destruction." Econometrica, Vol. 60 (1992), pp. 323-51.

[4] Almeida, P. And Kogut B. "Localization of Knowledge and the Mobility of Engineers in Regional Networks." Management Science, Vol. 45 (1999), pp. 905-916.

[5] Antonelli, C. "The Economics of Localized Technological Change". Kluwer Academic Publishers, Norwell, MA, 1995.

[6] Blundell, R. AND Bond, S. "GMM estimation with persistent panel data: an application to production functions", Econometric Reviews, $\operatorname{Vol}(19)$ (2000), pp. 321- 340.

[7] CincerA, M. "Firms' Productivity Growth and R\&D Spillovers: An Analysis of Alternative Technological Proximity Measures." Economics of Innovation and New Technology, Vol. 14 (2005), pp. 657-682.

[8] Gilson, R. J. "The Legal Infrastructure of High Technology Industrial Districts: Silicon Valley, Route 128, and Covenants not to Compete." New York University Law Review, Vol. 74 (1999), pp. 575-629.

[9] Grossman, G.M. And Helpman, E. "Innovation and Growth in the Global Economy". Cambridge, MIT Press, 1991.

[10] Inkmann, J. And Pohlmeier, W. "R\&D Spillovers, Technological Distance and Innovative Success". Paper presented at the Conference on "R\&D, Innovation and Productivity", Institute for Fiscal Studies, London, 1995.

[11] JAfFe, A. B. "Technological Opportunity and Spillovers of R\&D." American Economic Review, Vol. 76 (1986), pp. 984-1001.

[12] Kaiser, U., Kongsted H. And Rønde T. "Labor Mobility and Patenting Activity." CAM working paper no. 2008.

[13] Kaiser, U., Licht G., Rønde T. And Schneider C. "Patenting Activity in Denmark." CEBR paper, 2005. 
[14] Kim, J. AND MARSChKe, G. "Labor mobility of scientists, technological diffusion, and the firm's patenting decision." RAND Journal of Economics, Vol. 36 (2005), pp. 298-317.

[15] Levinsohn, J. And Petrin, A. "Estimating Production Functions Using Inputs to Control for Unobservables." Review of Economic Studies, Blackwell Publishing, Vol. 70 (2003), pp. 317-341.

[16] Maliranta, M., Mohnen, P. And Rouvinen P. "Is Inter-Firm Labor Mobility a Channel of Knowledge spillovers? Evidence from a Linked Employer-Employee Panel." Industrial and Corporate Change, Vol.18 (2010), pp. 1161-1191.

[17] Mundlak, Y. "Empirical Production Function Free of Management Bias." Journal of Farm Economics, Vol. 43 (1961), pp. 44-56.

[18] Olley, G. S. AND PAKes, A. "The dynamics of productivity in the telecommunications equipment industry." Review of Economic Studies, Vol. 69 (1996), pp. 245-276.

[19] OECD. "Economic Survey of Denmark." 2005.

[20] Petit, M.L. And Tolwinski, B. "Technology Sharing Cartels and Industrial Structure." International Journal of Industrial Organization, Vol. 15 (1996), pp. 77-101.

[21] Petrin, A., Levinsohn, J., Poi, B. "Production Function Estimation in Stata Using Inputs to Control for Unobservables". Stata Journal, 2004.

[22] Romer, P.M. "Endogenous Technological Change." Journal of Political Economy, Vol. 98 (1990), pp. 71-102.

[23] Rosenkopf, L. And AlmeidA, P. "Overcoming local search through alliances and mobility." Management Science, Vol. 49 (2003), pp. 751-766.

[24] SöDerbom, M. AND Bond, S. "Adjustment costs and the identification of Cobb Douglas production functions." IFS Working Papers, 2005.

[25] SöDerbom, M. "ERSA Training Workshop. Lecture 4: Estimation of Production Functions with Micro Data." 2009.

[26] Song, J., Almeida, P. And Wu, G. "Learning-by-Hiring: When Is Mobility More Likely to Facilitate Inter-firm Knowledge Transfer?." Management Science, Vol. 49 (2003), pp. 351-365.

[27] Van Beveren, I. "Total Factor Productivity Estimation: a Practical Review". Journal of Economic Surveys, forthcoming. 
[28] WindmeiJer, F. "A Note on R2 in the Instrumental Variables Model", Journal of Quantitative Economics, Vol.11 (1995), pp. 257-261.

[29] WoOlDRIDGE, J.M. "On estimating firm-level production functions using proxy variables to control for unobservables." Economics Letters, Vol. 104 (2009), pp. 112-114. 